\title{
A COMUNICAÇÃO SOCIAL COMO PORTA VOZ DO CORPO DE BOMBEIROS MILITAR PARA A PREVENÇÃO DE INCÊNDIO E ACIDENTES NO ESTADO DE PERNAMBUCO
}

Aldemir Justino da Silva ${ }^{1}$

\section{RESUMO}

Os incêndios são causas de sinistros a bens móveis, imóveis, florestas, entre outros, com consequentes perdas, não só materiais e econômicas, como também de vidas humanas. Assim, compete, prioritariamente, ao Corpo de Bombeiros Militar empreender ações para debelar os fogos, prestar orientações técnicas para segurança da população, bem como, desenvolver ações preventivas, pois, verificase que em diversas situações o descuido/desinformação acaba resultando em incêndios e acidentes. Neste sentido, ressalta-se a importância do Corpo de Bombeiros Militar de Pernambuco - CBMPE expandir e tornar mais efetiva a sua atuação preventiva, contando com o apoio do Centro de Comunicação Social para a criação de campanhas publicitárias de prevenção de acidentes e incêndios, utilizando diversos canais internos e externos para a divulgação, inclusive, por meio das mídias sociais e de convênios para o amplo alcance da sociedade do estado de Pernambuco.

Palavras-chave: Corpo de Bombeiros Militar de Pernambuco; Comunicação Social; Prevenção.

\footnotetext{
${ }^{1}$ Major do Corpo de Bombeiros Militar de Pernambuco. E-mail: aldemirjustino@hotmail.com
} 


\title{
SOCIAL COMMUNICATION OF FIRE DEPARTMENT FOR FIRE AND ACCIDENT PREVENTION IN THE STATE OF PERNAMBUCO
}

\begin{abstract}
Fires are causes of accidents to movable, immovable property, forests, among others, with consequent losses, not only material and economic, but also of human lives. Thus, it is primarily the responsibility of the Military Fire Brigade to take actions to quell the fires, provide technical guidance for the safety of the population, as well as develop preventive actions, as it turns out that in various situations, careless ness misinformation ends up resulting in fires. and accidents. In this sense, the importance of Fire Department of Pernambuco - CBMPE is emphasized to expand and make its preventive action more effective, with the support of the Social Communication Center for the creation of advertising campaigns for the prevention of accidents and fires, using several internal and external channels for dissemination, including through social media and agreements for the wide reach of society in the state of Pernambuco.
\end{abstract}

Key-words: Fire Departament of Pernambuco; Social Communication, Prevention. 


\section{INTRODUÇÃO}

O Corpo de Bombeiros Militar de Pernambuco, durante alguns anos esteve subordinado à Polícia Militar, contudo, após a emancipação, no dia 22 de julho de 1994,foi criada a estrutura da Corporação, por intermédio da Lei oํ 11.199, de 30 de janeiro de 1995, a qual previa em seu artigo 14, IV, sobre a comunicação social e ação comunitária. Hoje, este setor é denominado de Centro de Comunicação Social e atua planejando, coordenando e divulgando informações e atividades para a sociedade. Além disso, oferece um serviço eficiente de atendimento ao público, respeitando os princípios éticos e constitucionais voltados para a administração pública, sobretudo, o da legalidade, impessoalidade, publicidade, moralidade e eficiência.

Vale destacar as alterações ocorridas no decorrer dos anos no tocante à estrutura organizacional da Corporação, assim, a Lei de Organização Básica do Corpo de Bombeiro Militar de Pernambuco, Lei oㅜ 11.199/95, que versava sobre assuntos relativos à comunicação social e ação comunitária foi revogada pela Lei no 12.153, de 26 de dezembro de 2001, a qual em seu inciso IV, do artigo 30, passou a tratar sobre Assessoria de Comunicação Social subordinada ao Gabinete do Comando Geral. Anos mais tarde, a Lei no $12.153 / 01$ foi revogada pela Lei oㅜ 15.187, de 12 de dezembro de 2013 e, dada a importância da Comunicação Social, esta última, elevou o que antes era uma Assessoria para o atual Centro de Comunicação Social, o qual, além de estar diretamente ligado ao Gabinete do Comando Geral, define a criação de estrutura própria como um dos órgãos de apoio nesta nova legislação.

O Centro de Comunicação Social atua como comunicador das ações da Corporação dos Bombeiros Militares para a comunidade, a partir das explicações técnicas de ocorrência. Entre outros fatores, a Comunicação Social por ser técnica e direta evita informações errôneas de intermediários que não estejam ligados aos serviços específicos da caserna, como por exemplo, jornalistas, os quais podem externar o sinistro com dados incompletos ou incorretos, não garantindo desta feita a melhor informação para o público em geral. 
Além disso, é importante ter cautela no tocante à qualidade da informação a ser disseminada, a fim de evitar notícias falsas, pois, diante do avanço tecnológico e do uso massivo das mídias sociais, as informações se propagam de forma muito fácil e rápida. Ressalte-se os dados publicados pelo jornal Estado de Minas, no ano de 2018, os quais trazem que cientistas do Instituto de Tecnologia de Massachusetts dos Estados Unidos (MIT, na sigla em inglês), informam que "as notícias falsas se espalham na internet seis vezes mais rapidamente que as notícias verdadeiras. E esse resultado de nada tem a ver com a ação de robôs: é fruto do comportamento das pessoas" (FOLHA DE MINAS GERAIS, 2018, p. 1). Daí, a relevância do Centro de Comunicação Social, pois, além da informação elaborada em bases técnicas, outra característica da área de publicidade é o poder de persuasão, ou seja, o convencimento da população daquilo que pretende ser externado.

Diante do exposto, entende-se que o Centro de Comunicação Social dos Bombeiros Militares, é setor fundamental para disseminar informações, orientações e cuidados que podem contribuir para evitar/reduzir a incidência de sinistros, mediante criação de peças publicitárias e uso de mídias sociais, conforme será abordado no decorrer deste trabalho.

\section{BREVE HISTÓRICO DA PUBLICIDADE E PROPAGANDA NO BRASIL}

Os escritos do publicitário Marcio Carbaca Gonçales(1995) explicitam que a primeira publicidade realizada no Brasil teria sido por intermédio da carta de Pero Vaz de Caminha ao relatar à Dom Manuel, o rei de Portugal, as maravilhas do local descoberto, tratava-se da descrição da llha de Santa Cruz. Ocorre que após essa publicação, "a publicidade no Brasil perdurou por aproximadamente 300 anos, praticamente, de forma oral, com exceções das que eram realizadas nas capelas assim como as trocas de mercadorias" (GONÇALES, 1995, p 10).

Em que pese a semelhança entre as palavras, publicidade e propaganda não significam a mesma coisa, apesar de terem uso por alguns, de forma atécnica, como sinônimos. 
A publicidade é a arte de divulgar, tornar público por meio de técnicas uma ideia que pode ser comercial ou não com o intuito de obter a aceitação social. Ela é mais ampla que a propaganda tornando uma técnica de comunicação de grande amplitude. Já o anúncio publicitário ou publicidade é um gênero textual que promove um produto ou uma ideia sendo veiculado pelos meios de comunicação de massa: jornais, revistas, televisão, rádio e internet, bem como, em outdoors, panfletos, faixas ou cartazes na rua, no ônibus, no metrô etc.

A terminologia propaganda, por sua vez, derivada do latim propagare, que se origina de pangere, que significa mergulhar, plantar. Surgiu com o papa Gregório $\mathrm{XV}$ com o intuito de difundir a religião católica e supervisionar a propagação do cristianismo pelo mundo. No início foi uma atividade para promover um sistema ideológico da doutrina religiosa.

No Século XIX, um dia antes da invasão em Lisboa pelas tropas de Napoleão Bonaparte, houve a chegada ao Brasil do príncipe regente D. João, juntamente com a família real, e foi dada início à publicidade e propaganda tal qual a conhecemos. Os costumes e hábitos na nova sede da monarquia portuguesa, com a chegada do príncipe ao Rio de Janeiro, começaram a se modificar. Destaca-se entre as novas ideias do príncipe: a fundação do Banco do Brasil, a abertura dos portos brasileiros para o exterior, a criação das primeiras instituições de ensino superior e o primeiro jornal escrito. Iniciando a partir daí a imprensa brasileira. Há registros de que o primeiro anúncio publicitário tratou sobre imóveis e foi divulgado na Gazeta do Rio de Janeiro, este guarda semelhanças ao modelo que é utilizado atualmente.

A Empresa Canadense "Light", hoje sociedade anônima no Rio de Janeiro, foi a primeira a criar o departamento de relações públicas no Brasil em 1914, tendo como patrono Eduardo Pinheiro Lobo. Na década de 40, houve o desenvolvimento dos meios de comunicações, sobretudo na mídia impressa e eletrônica, em virtude da industrialização e a chegada das empresas internacionais ao nosso país. Contudo, a primeira indústria com uma identificação pátria a inaugurar o departamento de relações públicas foi a Companhia Siderúrgica Nacional, no ano de 1951. 
No decorrer do tempo, os profissionais da área de comunicação começaram a se inserirem nas agências de publicidade e propaganda, tendo na sequência a Companhia Nacional de Relações Públicas e Propaganda como a primeira empresa desse setor, criada no ano de 1952.

\section{A IMPORTÂNCIA DAS AÇÕES PREVENTIVAS NO CBMPE}

A atuação do Corpo de Bombeiros Militar de Pernambuco, no decorrer dos anos, deu importância não só às ações voltadas a debelar os sinistros ocasionados pelo fogo, salvamento de pessoas e bens, como também, ações preventivas. Desse modo, avançou por intermédio dos Centros de Atividades Técnicas - CATs, hoje expandidos por todo o território do Estado de Pernambuco, cujas análises técnicas realizam-se com base na Lei no 11.186, de 22 de dezembro de 1994, Código de Segurança Contra Incêndio e Pânico - COSCIP.

A Lei oㅜ 11.186/94 em seu artigo 3ํㅜ, parágrafo único, traz como uma das competências do Corpo de Bombeiros Militar de Pernambuco - CBMPE, a atuação de forma preventiva, executada pelos Centros de Atividade Técnicas - CATs, como segue:

Art. 3‥ Compete ao Corpo de Bombeiros Militar de Pernambuco - CBMPE, o estudo, a análise, o planejamento, a fiscalização e a execução das normas que disciplinam a segurança das pessoas e de seus bens contra incêndio e pânico em todo o Estado de Pernambuco, na forma prevista neste Código.

Parágrafo único - Para o cumprimento do disposto neste artigo, o Estado, por intermédio do CBMPE, efetivará a celebração de convênios, ajustes ou outros instrumentos congêneres, com órgãos da administração direta $e$ indireta federal, estadual ou municipal, bem como com entidades privadas. (LEI 11.186, 1994, p. 5, grifos nossos).

Assim, os CATs desempenham suas ações preventivas com base nesta legislação, mediante a realização de vistorias nos estabelecimentos comerciais, industriais e demais repartições públicas e privadas da administração direta e indireta, verificando locais onde o sistema preventivo esteja deficitário, seja pela falta de equipamentos ou inexistência da manutenção destes, promovendo orientações e 
dando prazos para a correção. Além disso, participa de entrevistas em rádios e TVs para orientação ao público em geral, bem como, articula reuniões com os gestores municipais, principalmente, em períodos de grandes eventos, para orientar quanto à segurança, discutindo a melhor forma de realização destes.

Vale considerar, ainda, que conforme transcrito no trecho da Lei 11.186/94, o legislador já previa no início dos anos 90 que o fortalecimento das prevenções se daria, também, por intermédio de convênios do CBMPE com órgãos da administração pública, bem como, por outros instrumentos administrativos com as empresas privadas. Entende-se que esta prerrogativa de celebração de convênios, possibilita parcerias para a implementação de outras ações preventivas tornando ainda mais efetiva a atuação do CBMPE.

No tocante às ações voltadas para a prevenção de incêndios, destaca-se o artigo publicado, no ano de 2015, pelo Tenente Coronel BM Cristiano Corrêa, do CBMPE, o qual apresenta o mapeamento de incêndios em edificações na cidade de Recife, entre os anos de 2011 a 2013, com padronização sugerida pela Liga dos Comandantes Gerais do Corpo de Bombeiros. A pesquisa apontou que "os objetos frequentemente mais atingidos nos incêndios são: cadeiras em madeiras, colchões, camas em madeiras, geladeiras, panelas em metal, televisores, ventiladores, fogões e guarda-roupas em madeira" (CORRÊA, et al., 2015, p.31). Ao contrário do que se pensava, as edificações residenciais e unifamiliares são mais propícias aos incêndios que os estabelecimentos comerciais, industriais etc. $O$ autor conclui pontuando que:

\begin{abstract}
A análise de estatísticas de incêndio em edificações em uma cidade pode revelar faces importantes da dinâmica dos sinistros locais, fomentando políticas públicas mais adequadas e customizadas, gerando informações e inteligência para os serviços de combate a incêndio, incitando campanhas preventivas mais eficazes e estabelecendo objeto de análises acadêmicas pautadas em uma realidade de atendimento aos sinistros (CORREA, et al., 2015, p.31, grifo nosso).
\end{abstract}

Noutro estudo realizado no estado do Pará, entre os anos de 2008 a 2013, Erika de Sousa et al (2015) abordaram quais os tipos e causas de incêndios, se acidental, natural, criminoso etc. Verificando que nesse período, de forma homogênea, ocorreram em sua maioria incêndios em edificações e acidentais. Este 
trabalho constatou, ainda, que há uma necessidade de conscientização e esclarecimentos para a população quanto aos riscos e perigos ocasionados face aos descuidos, uma vez que, em sua maior parte, os incêndios foram acidentais. $\mathrm{Na}$ conclusão do estudo pontua-se que: "políticas públicas voltadas para a educação ambiental e a ampliação da fiscalização para mitigar as infrações responsáveis pela maioria desses incêndios poderiam reduzir os números de ocorrências e assim minimizar os riscos ambientais" (SOUSA et al, 2015, p.2472), corroborando com a relevância do presente trabalho.

Como pode ser visto, nos estudos supracitados, pugna-se por uma didática preventiva para evitar as ocorrências destes incidentes e incêndios acidentais. Neste sentido, menciona-se, por exemplo, uma ocorrência corriqueira que resulta em incêndios, uma vez que grande parte da população brasileira é religiosa, diz respeito ao esquecimento de velas acesas, sobretudo, próximas a locais inflamáveis, especialmente, no quarto onde uma pequena ventania ou um mau posicionamento poderá derrubá-la e ocasionar um incêndio, além de outros casos, tais como: choque elétrico, vazamento de gás, celulares carregando em locais inadequados e panelas esquecidas no fogo, entre outros.

Neste sentido, considera-se que o CBMPE poderá contar com o apoio especializado do Centro de Comunicação Social para a propagação de informações nas mídias sociais, bem como, a criação de peças de publicidade e propaganda, direcionadas a cuidados preventivos, a serem difundidas junto à população com o intuito de evitar acidentes e os consequentes sinistros.

No intuito de melhor compreender as possibilidades da publicidade e propaganda e descrever os tipos de propagandas que existem e mostrar aquele que comumente é utilizado pela Corporação, buscou-se o aporte teórico nos estudos de Neil Patel, o qual define:

Propaganda ideológica: tem o objetivo de difundir ideologias e convicções de um determinando grupo sobre outro, de maneira a orientar todo o seu comportamento social;

Propaganda política: forma de persuasão ao eleitor por meio do horário político, seja ele televisivo ou outros meios de comunicação, a exemplo do whatsapp;

Propaganda governamental: são técnicas utilizadas que procuram criar e fortalecer a imagem do governo, prestar contas para a população, divulgar eventos e campanhas de conscientização não podendo promover a imagem de uma autoridade específica; 
Propaganda institucional: atua essencialmente na criação e fortalecimento da imagem da marca na mente dos consumidores. Costuma-se apelar para aspectos emocionais, não estando focadas nas vendas de produtos, mas em preencher outras necessidades das empresas com o objetivo de criar uma imagem positiva da marca;

Propaganda social: aqui o viés não tem qualquer relação aparente com aspectos comerciais, isso porque as técnicas desse tipo de estratégia são voltadas para a conscientização de alguma causa social;

Propaganda de produto: o seu objetivo e promover um produto para 0 público, ressaltando os seus pontos positivos, seus diferenciais e potencialidades em relação a concorrência;

Propaganda de serviços: utilizam técnicas com o objetivo de estimular a contratação. É um modelo parecido com o anterior, mas que se diferencia nas questões especificas do mercado de serviço, em especial naquilo em que o seu público deseja receber como proposta de experiência; Propaganda comparativa: serve para demonstrar a superioridade de suas soluções, apontando no que ela e melhor e como isso favorece o consumidor;

Propaganda enganosa: dá margem aos principais questionamentos morais e éticos, consiste em oferecer o que não tem, ou seja, mostrar características de um produto ou serviço que não existe de fato, apenas para chamar a atenção do consumidor e aumentar as vendas;

Propaganda religiosa: é também utilizada para divulgar questões morais e éticas especificas, incluindo o aborto e a controvérsia sobre o ensino religioso nas escolas (PATEL, 2020, p. 6-17).

A partir da análise fundamentada nos estudos de Neil Patel, conclui-se que a propaganda normalmente utilizada no CBMPE é a: governamental, uma vez que ao adquirir novos equipamentos de proteção individual, operacional ou viaturas, procura-se deixar a população informada por meio de publicações nos meios de comunicação, principalmente, o televisivo; institucional, ao demonstrar a importância da aquisição dos novos equipamentos para as atividades de salvamento da Corporação; social, no momento em que por meio de entrevistas demonstram como proceder para que seja evitado, por exemplo, o vazamento de gás nas residências.

Em seu trabalho monográfico, Weber (2014, p.13) relata que "uma empresa que sabe utilizar todas as ferramentas comunicacionais disponíveis e consegue passar informações claras e precisas disponíveis aos seus públicos, dentro e fora da empresa, alcança com mais facilidade os seus objetivos". Complementando esse raciocínio, Kunsch apud Weber (1997, p. 116) descreve que "para as organizações em geral é muito importante a integração das suas atividades de comunicação, em função do fortalecimento do conceito institucional, mercadológico e corporativo com a sociedade". 
Diante das peculiaridades dos tipos de propagandas e observações externadas acima, pondera-se se não haveria condições de realizá-las de forma massificada com a sociedade, com o intuito de dar não só uma maior visibilidade das atividades desenvolvidas pela Corporação, bem como, viabilizar de forma simples e eficaz, informações diretas de prevenção à população, sobretudo, as mais carentes evitando, assim, perdas humanas e/ou prejuízos financeiros e patrimoniais.

Desta forma, sugere-se que o Centro de Comunicação Social possa criar materiais publicitários, campanhas preventivas e mídias sociais para disseminar informações, pois elas são de grande valia para subsidiar a sociedade de uma forma geral sobre a importância de ficar atento, tomar cuidados e evitar acidentes.

\section{CBMPE E PUBLICIDADE: ALIADAS EM AÇÕES PREVENTIVAS}

A previsão legal de propaganda e publicidade, está na Lei 4.680, de 18 de junho de 1965, a qual explicita no seu artigo 4ำ que:

São veículos de divulgação, para os efeitos desta Lei, quaisquer meios de comunicação visual ou auditiva capazes de transmitir mensagens de propaganda ao público, desde que reconhecidos pelas entidades e órgãos de classe, assim considerados as associações civis locais e regionais de propaganda bem como os sindicatos de publicitários. (Lei 4.680, 1965, p.1grifos nossos)

Então, com base no que descreve a própria legislação que regula a profissão de publicitário e agenciador de propaganda, pode ser utilizado qualquer veículo de divulgação, no sentido de todo o meio de comunicação válido que transmita a informação desejada ao público alvo. Em outras palavras, a publicidade na prevenção de sinistros é a forma de propagação de ideias, de forma criativa e clara, por meio de veículos de divulgação, tal como prescreve as legislações, contribuindo para informações e sugestões de atitudes mais assertivas por parte da população.

\subsection{Criação publicitária para prevenção de acidentes e incêndios}


Conforme dito anteriormente, este trabalho propõe que o Centro de Comunicação Social possa criar peças publicitárias com linguagem e imagens claras e simples, que transmitam informações preventivas, baseadas nas causas de incêndio e acidentes mais frequentes, de forma a contribuir para a redução dos sinistros. Além disso, pode ser afixado um QR Code direcionando o público para a página do Corpo de Bombeiros Militar de Pernambuco onde constarão informações complementares sobre os mais diversos tipos de cuidados preventivos de acidentes e incêndios.

Este trabalho não tem a pretensão de esgotar o assunto, contudo, sugere abaixo alguns temas que podem ser abordados pelo Centro de Comunicação Social em peças de publicidade nas campanhas preventivas:

1) emergência 193: informar o número de telefone para o contato imediato da população em casos de urgência/emergência, ressaltando que a ligação é gratuita, bem como, as consequências ao mau uso da ferramenta (trotes), expondo as penalidades legais;

2) veículos perto de hidrantes: avisar para que as pessoas não estacionem os seus veículos perto de hidrantes, sobretudo os de fachada, com o intuito de facilitar as manobras operacionais em caso de ocorrência de incêndios;

3) desligar os aparelhos elétricos: orientar ao usuário que for deixar o estabelecimento fechado por longos períodos desligue a chave geral de eletricidade, com o intuito de evitar curto-circuito;

4) ligações em T: aconselhar a não ligação de diversos equipamentos na mesma tomada, sob risco de sobrecarregar os circuitos elétricos, possibilitando curtos-circuitos;

5) quadro de disjuntores: recomendar à população a procurar profissional habilitado para realizar as instalações, primando pela distribuição correta do circuito elétrico nas residências;

6) extensões elétricas: evitar a utilização de extensões nas residências, mas em caso de necessidade, utilizar aquelas que são aprovadas pela Associação Brasileira de Normas Técnicas - ABNT; 
7) carga de celulares: alertar para que os celulares não fiquem ligados a noite enquanto a família dorme, pois poderão causar incêndios por combustão espontânea, tanto dos celulares como dos carregadores;

8) produtos inflamáveis: ter atenção para não acender fósforos ou fumar próximo aos produtos inflamáveis, onde poderá ocasionar explosões;

9) fogos de artifício: no período de festas juninas informar sobre os riscos de acidentes pelo seu mau uso;

10) balões juninos: enfatizar para não soltar balões, os quais poderão ocasionar incêndios, principalmente em áreas florestais;

11) acondicionamento de materiais: orientar para não guardar solventes, tintas ou outros materiais inflamáveis em recipientes inadequados, a fim de evitar combustão acidental;

12) guarda de materiais: destacar os riscos de deixar produtos inflamáveis, de limpeza residencial, medicamentos e substâncias tóxicas, ao alcance de animais domésticos ou crianças que podem ingerir e intoxicar-se ou causar acidentes;

13) vazamento em botijões de gás: advertir que ao sentir o cheiro característico da mercaptana não deve acender luzes, mas, sim, deixar o ambiente ventilado, abrindo portas e janelas para a dissipação dos gases, chamando em seguida o Corpo de Bombeiros Militar para as providências técnicas;

14) gás de cozinha: manusear com segurança o botijão de gás de cozinha, uma vez que o registro e a mangueira devem ser certificadas pela ABNT, com validade de 5 anos. Ressaltando a importância de verificar se há vazamento utilizando esponja com água e sabão;

15) afogamento: manter baldes e bacias viradas de cabeça para baixo, supervisionando as crianças durante o banho. Não deixar crianças brincando sozinhas em piscinas ou similares;

16) animais pecconhentos: procurar ter cuidado ao visitar locais que tenha vegetação nativa, procurando saber quais os tipos de animais existentes naquela 
área, com o intuito de evitar o contato com animais peçonhentos como cobras, tipo: jararaca, cascavel, coral verdadeira etc;

17) elevadores: atentar antes de entrar no elevador verificando se o piso encontra-se no compartimento; verificar a capacidade de pessoas; não fumar dentro do elevador, etc.

\subsection{Uso das mídias sociais}

Diante da expansão das tecnologias de informação e do uso massivo destas, cada vez mais, as mídias sociais estão presentes no cotidiano das pessoas sendo utilizadas com o intuito de buscar entretenimento, bem como, informações que consideram relevantes.

Daí a necessidade de se ter especial cuidado com as mídias institucionais, mantendo o site corporativo do CBMPE atualizado, com dados e orientações de interesse para a comunidade, com apresentação visual atrativas e com fácil acesso às informações. Além disso, recorrer as mídias sociais, tais como: Twitter, Facebook, e Instagram e site institucional como canais para conexão, interação e compartilhamento de conteúdos, quais sejam: acesso a serviços, orientações preventivas, informações técnicas, acesso a dados estatísticos e prestação de contas para a sociedade.

Considera-se, ainda, que estas mídias sociais corporativas possam ser utilizadas como canais para a ampla divulgação dos materiais publicitários produzidos para a prevenção de acidentes e incêndios.

Destaca-se que ao falar sobre os planos de significação corporativa, Eduardo Camilo explicitou que as mensagens divulgadas nas páginas que constituem o corpo do site:

São caracterizadas por significações complexas, compostas por uma multiplicidade de signos dotados das mais variadas substâncias expressivas, mas suportados por um conjunto restrito, de pelo menos, quatro matérias. É o caso da natureza verbal (palavras impressas e ou pronunciadas), iconográfica (imagens estáticas e/ou movimentos), gráfica (grafismos animados e/ou estáticos-cromatismos etc com a particularidade de poderem incidir sobre outras matérias) e sonora (ruídos, efeitos sonoros, músicas, etc.) (CAMILO, 2003, p. 33) 
A partir dos planos de significação pontuados por Camilo, percebe-se a complexidade da transmissão de informações técnicas com base no que preceitua a publicidade. Verifica-se que as ferramentas de comunicação social utilizadas pelo CBMPE se enquadram em pelo menos três das características explicitadas pelo autor, quais sejam: natureza verbal, iconográfica e gráfica e, a depender da mensagem, pode-se ainda usar a sonora.

Dessa forma, diante da complexidade da transmissão de informações técnicas entende-se que os materiais para a comunicação externa devam ser elaborados por profissionais especializados do Centro de Comunicação Social, conforme citado anteriormente neste trabalho.

\subsection{Uso de outdoors, banners e/ou painéis}

Criadas as peças publicitárias voltadas à prevenção de incêndios, estas podem ser divulgadas por meio de outdoors ou banners afixados em locais estratégicos e de grande visibilidade, na frente dos prédios de grupamentos do Corpo de Bombeiros ou em quartéis da Polícia Militar, os quais estão presentes em todas as regiões do Estado de Pernambuco.

Além disto, podem-se utilizar painéis com os anúncios publicitários afixados nas laterais das viaturas operacionais e/ou dos veículos do setor administrativo, inclusive, esta ação é inspirada na experiência realizada pelo Corpo de Bombeiros Militar do Distrito Federal (ver modelo no anexo).

Ressalte-se no anexo deste trabalho o modelo dessa publicidade, onde, de forma bem didática, o CBMDF afixou um painel com anúncio na parte lateral de uma viatura operacional com os dizeres: "pequenas chamas podem se tornar grandes incêndios", apresentando o percentual de ocorrências e ilustrando os dados com a imagem de uma vela acesa, chamando atenção para possíveis descuidos no uso desse artefato, que podem acarretarem incêndio, aludidos nas chamas expostas na imagem de fundo. 


\subsection{Convênios para divulgação de materiais publicitários}

Por outro lado, paralelamente às ações nas mídias sociais, outdoors, banners e/ou anúncios afixados nas viaturas, pode-se, ainda, divulgar as mensagens publicitárias preventivas de acidentes e incêndios nos boletos de cobrança das taxas de incêndio e expandir o alcance dessa ação por convênios.

O CBMPE pode realizar convênios, por exemplo, com a Companhia Pernambucana de Saneamento-COMPESA, com o intuito de que sejam colocados nas suas contas mensais de água, mensagens de prevenção de incêndios e acidentes, bem como, QR Code para acesso às informações detalhadas, no mesmo padrão que é disposto nos veículos operacionais. Tendo, dessa forma um maior alcance dessas informações uma vez que chegará a grande número de residências e estabelecimentos, inclusive, dos que têm menor renda.

As informações do Instituto Brasileiro de Geografia e Estatística - IBGE, em sua página oficial, explicitam que, no ano de 2019. Pernambuco tinha uma população estimada em 9.557.071 (nove milhões quinhentos e cinquenta e sete mil e setenta e uma) pessoas e no site oficial da Companhia Pernambucana de Saneamento - COMPESA, consta uma abrangência no serviço de abastecimento de água e coleta de esgoto em 173 (cento e setenta e três) dos 185 (cento e oitenta e cinco) municípios de Pernambuco.

Considerando que a COMPESA não traz em seu site informações do quantitativo de clientes atendidos por ela, fez-se uma estimativa por analogia, verificando-se, de acordo com levantamento realizado, que a CELPE informa capilaridade nos 185 (cento e oitenta e cinco) municípios como atendimento a 3.696.164 (três milhões, seiscentos e noventa e seis mil, cento e sessenta e quatro) pessoas. Com base nesse levantamento, estima-se que a COMPESA atenda a, pelo menos, 3.000.000 (três milhões) de pessoas em todo o Estado, correspondendo a terça parte da população pernambucana.

Inegável o alcance que a COMPESA poderá proporcionar, com a realização de um convênio para que as informações preventivas do CBMPE sejam difundidas e reforçadas em ambientes onde a viatura não tem condições de chegar ou até mesmo como reforço destas informações. 
Outra proposta de convênio a ser firmado é com o Grande Recife Consórcio de Transportes, o qual relata em sua página oficial na internet que realiza mais de 25 (vinte e cinco) mil viagens e transporta cerca de 1,8 milhão de pessoas, diariamente. Dessa forma, considera-se que os anúncios do CBMPE podem ser afixados no interior ou na parte traseira dos ônibus, realizando uma ampla divulgação pela cidade, uma vez que os coletivos são vistos diuturnamente em várias áreas na região metropolitana do Recife.

\section{CONCLUSÃO}

Como dito anteriormente, este trabalho não se propôs a esgotar as possibilidades de ações de prevenção de incêndios e acidentes por parte do CBMPE, mas, buscou agregar sugestões para a expansão destas, bem como, amplitude do alcance na sociedade, mediante o uso de equipamentos internos e convênios.

De acordo com o que fora exposto e, ciente de que a Corporação conta com a expertise do Centro Comunicação Social, considera-se que este setor pode ser um grande aliado nas ações preventivas, mediante a produção de materiais publicitários relativos à prevenção de incêndios e acidentes. Estas peças publicitárias devem ter ampla divulgação, sugerindo-se o uso das mídias sociais, outdoors, banners, painéis em viaturas operacionais e/ou administrativas, bem como, celebração de convênios, ajustes ou outros instrumentos congêneres, com órgãos da administração direta e indireta federal, estadual ou municipal, bem como com entidades privadas, no intuito de ampliar o alcance das informações junto à população.

Além disso, ressalta-se que afora as campanhas permanentes, deve ser dada atenção especial aos grandes eventos do Estado, uma vez que, diante da tradição cultural de Pernambuco ocorrem diversos tipos de festividades, a exemplo de Carnaval e São João, os quais agregam pessoas de todas as partes do país e do mundo. Desta forma, entende-se que sejam necessárias campanhas direcionadas as orientações preventivas nos períodos que antecedem e durante os eventos festivos, os quais, certamente, alertam a população sobre cuidados e evitam acidentes. 
Ressalte-se o reconhecimento dos esforços empreendidos pelo Corpo de Bombeiros Militar de Pernambuco para a prevenção de sinistros e, por esse motivo, considera-se importante desenvolver outras ações preventivas, para além dos Centros de Atividades Técnicas - CATs, propondo-se que seja agregado o trabalho do Centro de Comunicação Social, para uma maior efetividade nos resultados que se pretendem, ou seja, salvaguardar vidas humanas e seus patrimônios.

\section{REFERÊNCIAS BIBLIOGRÁFICAS}

BRASIL. Constituição (1988). Constituição da República Federativa do Brasil. Brasília, DF: Senado Federal: Centro Gráfico, 2020.

. Lei 4.680/65.Dispõe sobre o exercício da profissão de Publicitário e de Agenciador de Propaganda e dá outras providências.Disponível em <http://www.planalto.gov.br/ccivil 03/LEIS/L4680.htm>. Acesso em 05 mai 2020.

CEARA. Prevenção e Controle de Sinistros I. Apostila do Curso Técnico em Segurança do Trabalho da Escola Estadual de Educação Profissional - EEEP. [entre 2007 a 2015]. Disponível em <file:///C:/Users/Acer/Desktop/CBMPE/Artigo/Comunicacao\%20Social/seguranca do trabalho prevencao e controle de sinistros I.pdf>. Acesso em 05 mai 2020.

CORREA, Cristiano et. al, . Mapeamento de incêndios em edificações: um estudo de caso na cidade do Recife. Disponível em:

<file:///C:/Users/Acer/Desktop/CBMPE/Artigo/Comunicacao\%20Social/tipos\%20de\% 20materiais\%20incendio\%20RECIFE\%20Cristiano.pdf>. Acesso em 06 mai 2020.

DISTRITO FEDERAL. Painéis em viaturas - CBMDF. Disponível em $<$ https://www.cbm.df.gov.br/6365-paineis-em-viaturas-cbmdf> . Acesso em 05 mai 2020.

EDUARDO, Camilo. Da importância do espaço-informação na expressão de uma territorialidade corporativa. Portugal: 2003. Disponível em: file:///C:/Users/Acer/Desktop/CBMPE/Artigo/Comunicacao\%20Social/camilo eduard o ico2 internet compromocional.pdf. Acesso em 06 mai 2020.

GONÇALES, Marcio Carbaca. Publicidade e propaganda. Curitiba: IESDE Brasil S.A, 2009.

IBGE - Instituto Brasileiro de Geografia e Estatística. Cidades e Estados. 2019. Disponível em <https://www.ibge.gov.br/cidades-e-estados/pe.html>. Acesso em 05 mai 2020. 
KUNSCH, Margarida Maria Krohling. Planejamento de relações públicas na Comunicação Integrada. 3 ed. São Paulo: Summus, 1986.

LEDUC, Robert. Propaganda: uma força a serviço da empresa. São Paulo: Atlas, 1977.

PATEL, Neil. O que é propaganda?. Disponível em $<$ https://neilpatel.com/br/blog/oque-e-propaganda/>. Acesso em 05 mai 2020.

PERNAMBUCO. Companhia Pernambucana de Saneamento S/A - COMPESA. Disponível em:<https://servicos.compesa.com.br/historia-e-perfil/>. Acesso em 05 mai 2020. 
Revista Científica do Corpo de Bombeiros Militar de Pernambuco

Artigo Publicado no Vol.07 N.20 - Edição Especial 2021 - ISSN 2359-4829

Versão on-line disponível em: http://www.revistaflammae.com

CBMPE Institucional [Secretaria de Defesa Social]. Recife, 2020.

Disponível em: https://www.lai.pe.gov.br/cbmpe/. Acesso em 20 abr. 2020

.LEI No 11.199, DE 30 DE JANEIRO DE 1995. [Secretaria de Defesa Social]. Recife, 2020. Disponível em: http://legis.alepe.pe.gov.br/texto.aspx?id=6204\&tipo=TEXTOORIGINAL. Acesso em 20 abr. 2020

. LEI № 12.153, DE 26 DE DEZEMBRO DE 2001. [Secretaria de Defesa Social]. Recife, 2020. Disponível em: http://legis.alepe.pe.gov.br/texto.aspx?id=2512\&tipo=TEXTOORIGINAL. Acesso em 20 abr. 2020

.LEI № 15.187, DE 12 DE DEZEMBRO DE 2013. [Secretaria de Defesa Social]. Recife, 2020. Disponível em: https://legis.alepe.pe.gov.br/texto.aspx?tiponorma $=1$ \&numero $=15187 \&$ complem ento $=0 \& a n o=2013 \&$ tipo $=\& u r l=$. Acesso em 20 abr. 2020

Grande Recife Consórcio de Transportes. Recife, 2020. Disponível em: <https://www.granderecife.pe.gov.br/sitegrctm/institucional/historico/>. Acesso em 06 mai 2020.

SOUSA, Erika de. et al. Incêndios oficializados no estado do Pará: uma visão

panorâmica dos tipos e causas. Disponível em: ENCICLOPÉDIA BIOSFERA,

Centro Científico Conhecer - Goiânia, v.11 n.21; file:///C:/Users/Acer/Desktop/CBMPE/Artigo/Comunicaca0\%20Social/incendios \%20of icializados\%20causas\%20PARA.pdf. Acesso em 05 mai 2020.

WEBER, Camila Hepfner. Gerenciamento de crises: o desempenho fundamental do profissional de relações publicas. Disponível em: <file://C:/Users/Acer/Desktop/CBMPE/Artigo/Comunicacao\%20Social/Trabalho\%2 $\underline{\underline{0 d}}$ e\%20Conclusão\%20de\%20Curso Final\%20gerenciamento\%20de\%20crises.pdf>. Acesso em 06 mai 2020. 


\section{Revista FLAMMAE}

Revista Científica do Corpo de Bombeiros Militar de Pernambuco

Artigo Publicado no Vol.07 N.20 - Edição Especial 2021 - ISSN 2359-4829

Versão on-line disponível em: http://www.revistaflammae.com

\section{ANEXO}

\section{PAINÉIS EM VIATURAS - CBMDF}

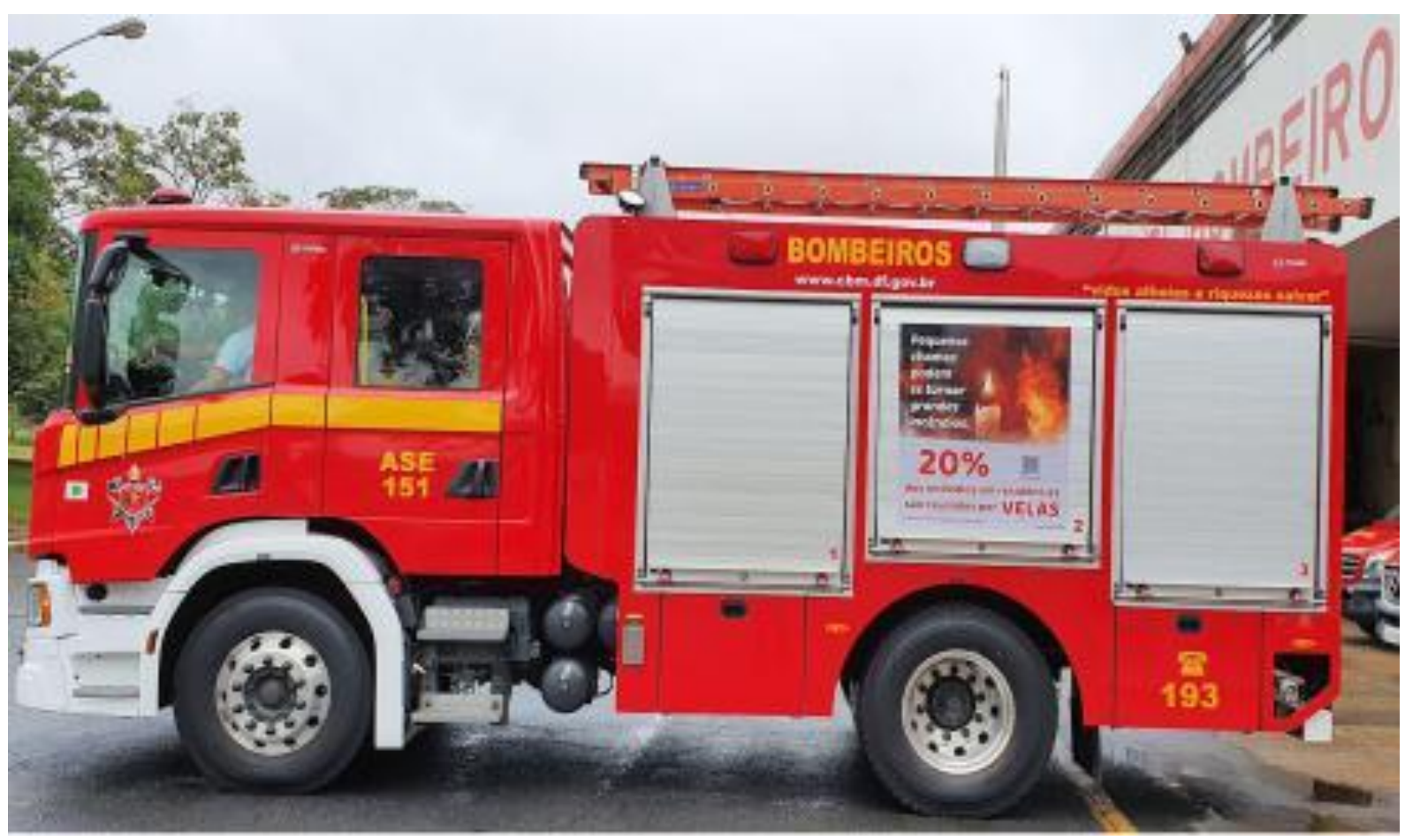

FONTE: Site do CBMDF. 